\title{
Fortalecimiento de la Protección al Consumidor Financiero Frente a la Actividad Contractual Bancaria Nacional e Internacional
}

\section{Strengthening of the financial consumer protection facing the national and international bank contractual activity}

\begin{abstract}
NATTALY CALONJE LONDOÑO
Candidata al título de Abogada de la Universidad Santo Tomás. Auxiliar de Investigación del Proyecto "Globalización del Derecho Privado", adscrito al "Proyecto Globalización del Derecho", dirigido por la Deutsche Gesellschaft für die Technische Zusammenarbeit (GTZ), y ejecutado por la Universidad Santo Tomás en Convenio con la GTZ.

Candidate to the title of attorney at law from the Santo Tomas University. Investigation collaborator from the project "globalization of private law", subscribed to the "globalization of law project", directed by the Deutsche Gesellschaft für die Technische Zusammenarbeit (GTZ), and executed by the Santo Tomas University in association with the GTZ.
\end{abstract}

\section{Dirigido por: Jorge Ricardo Palomares LL-M ${ }^{1}$}

Fecha de recepción: 23 de mayo de 2011 Fecha de evaluación: 30 de mayo de 2011 Fecha de aprobación: 8 de junio de 2011

RESUMEN: El presente artículo busca explicar, partiendo del concepto de Interés Público en el Ordenamiento Jurídico colombiano, cómo la Autonomía Privada de la

\footnotetext{
${ }^{1}$ Abogado de la Universidad Santo Tomás. Curso de Posgrado en Conducción y Gerencia de Instituciones Públicas, de la Universidad Nacional del Litoral-Argentia (Programa TOP). Legum Magister (LL-M) de la Universität KonstanzAlemania. Docente Tutor de la Maestría en Derecho Público, Universidad Santo Tomás. Investigador del Proyecto "Globalización del Derecho Privado", auspiciado por la GTZ y la Universidad Santo Tomás.
} 
Voluntad de agentes bancarios es restringida a través de la actuación estatal -en virtud de la cláusula general de competencia-, especialmente en la selección de normas contractuales, que pueden provenir de normas internacionales -como la nueva lex mercatoria-, y en ciertos comportamientos, tomando como punto de referencia la Ley 1328 de 2009, que protege al Consumidor Financiero.

PALABRAS CLAVE: Actitividad Bancaria, Interés Público, Cláusula General de Competencia, Autonomía Privada de la Voluntad, Consumidor Financiero, Ley 1328 de 2009.

ABSTRACT: This article seeks to explain, based on the concept of Public Interest in the Colombian legal system, how the private autonomy of the will of banking agents is restricted by state action "under the general clause on competition, especially in selection of contractual rules, which may come from international standards, as the new lex mercatoria, "and in certain behaviors, taking as reference the 1328 Act of 2009, which protects the Financial Consumer.

KEY WORDS: Financial Activity, Public Interest, Principle of Legality, Private Autonomy of the Will, Financial Consumer, "Ley 1328 de 2009".

Tipo de Artículo: Reflexión Académica. 


\section{INTRODUCCIÓN}

Las operaciones bancarias se rigen actualmente por estándares internacionales fijados tanto por Organizaciones Internacionales como agentes privados. Dichos estándares, considerados por algunos autores como instrumentos de la Nueva Lex Mercatoria, son aplicados por los Bancos a fin de tener un funcionamiento uniforme en cada uno de los países donde tienen filiales. Sin embargo, los bancos deben tener también como referente obligatorio las normas nacionales y determinar cuáles pueden ser suplidas por los estándares internacionales y cuáles deben ser cumplidas obligatoriamente. Ejemplo de una de estas normas con carácter obligatorio a nivel nacional es la ley 1328 de 2009, por la cual se dictan normas en materia financiera, de seguros, del mercado de valores y otras disposiciones. Dicha ley contiene, en miras a proteger a consumidores y usuarios financieros, fuertes medidas en materia de contratación, mediante la creación de obligaciones especiales para los bancos y derechos específicos para el consumidor bancario, entre otros. Estas medidas de protección a los consumidores financieros aplican también a aquellos bancos que deseen ingresar o constituir filiales en Colombia, de manera que, al ingresar al territorio colombiano, no entren en contradicción con normas nacionales en la materia.

La elección de normas -bien sean estándares internacionales o leyes nacionalespor parte de los bancos, es posible mediante el ejercicio de su Autonomía Privada de la Voluntad (en adelante APV), es decir, en materia de contratación bancaria la 
Nueva Lex Mercatoria tiene cabida sólo en la medida en que los bancos pueden elegir normas a aplicar y asi mismo desarrollar su APV. Pero, es necesario que ésta APV tenga una restricción si la legislación -especialmente colombianaestablece normas de obligatorio cumplimiento -o normas imperativas-. En el caso de la ley 1328 de 2009, es necesario determinar si las normas que protegen al consumidor financiero -objeto de este trabajo- imponen fuertes medidas a los bancos, constituyen en sí restricciones a la APV y condicionan el ingreso de nuevos agentes bancarios en el mercado colombiano.

Para ello, el trabajo plantea como interrogante el cómo pueden operar los bancos al tener como referente la ley 1328 de 2009. Dicha cuestión se desarrollará básicamente en tres momentos: en el primer momento se analizará el concepto de Interés Público en el Ordenamiento Jurídico colombiano como legitimante para la intervención estatal (I); posteriormente se analizará el Principio de la APV y su estado actual en el Derecho colombiano (II) y; finalmente se analizará si en la ley 1328 existen fuertes limitantes a la APV de los bancos a fin de que con esta se proteja al consumidor.

Esta pregunta se va a desarrollar a partir del concepto de actividad financiera como de interés público en Colombia, el concepto de servicio público, la limitación de la Autonomía privada de la voluntad en pro del interés general (bien común), mediante una intervención inversa, es decir, el legislativo, administrativo y judicial, la contratación bancaria, entre otros. 


\section{La Contratación Bancaria y el Interés Público en el Ordenamiento Colombiano}

\section{A. Concepto de Interés Público}

La actividad financiera es, de acuerdo a los artículos 150 Numeral 19 literal d, 189 Numerales 21 y 22, y 335 de la Constitución Política de 1991, objeto de intervención y regulación estatal (IBAÑEZ NAJAR, 2006: Pág. 73).

El artículo 335 de la Constitución Política de Colombia expresa que las actividades financiera, aseguradora y cualquier otra relacionada con el manejo, aprovechamiento e inversión de los recursos de captación a las que se refiere el literal d) del numeral 19 del artículo 150 son de interés público y sólo pueden ser ejercidas previa autorización del Estado, conforme a la ley, la cual regulará la forma de intervención del Gobierno en estas materias y promoverá la democratización del crédito.

El art. 335, ubicado en el título XII, Capítulo 1ํ de la Constitución Política, delimita el concepto de "actividad" sólo a aquellas realizables en el mercado, es decir, operaciones de tipo económico, que se desarrollan a través la oferta y la demanda, y que forman un conjunto de transacciones mercantiles de bienes y servicios, que buscan satisfacer las necesidades de los consumidores bancarios, lo anterior con base a que el comercio busca beneficiar a productores y consumidores. 
Asimismo no toda actividad económica está comprendida en este artículo. Solo las actividades que tengan que ver con ciertos campos del mercado son las que facultan al Estado para intervenir, en concreto el artículo se refiere a operaciones de captación masiva de dinero. (Por ejemplo en el caso del sector real, el artículo no le da al Estado la facultad de intervenir).

Dichas actividades, Según el artículo 335 de la Constitución de 1991 son de interés público. Esto puede deberse a que garantizan el adecuado flujo de capitales, es decir, las entidades financieras "filtran" la mayoría de los dineros del sector de la economía real. Así, las personas pueden tener acceso al conjunto de bienes y servicios que proporciona la economía, de una manera eficiente y adecuada, lo que lleva a que la actividad financiera sea uno de los motores más importantes para el desarrollo de la sociedad, y así posicionarse como de interés público. El legislador ${ }^{2}$, considera la actividad bancaría de interés público por existir "un criterio evidente de necesidad por cuanto, por regla general, la población requiere acceder a un producto o servicio financiero con el ánimo de alcanzar un bienestar económico y que existe una relación contractual generalmente asimétrica.

La relación que se crea entre las dos partes en la instrumentación de un servicio financiero es, por principio, asimétrica por cuanto una de las partes, la institución

\footnotetext{
${ }^{2}$ CONGRESO DE LA REÚBLICA, Cámara de Representantes, Proyecto 282 de 2008: por la cual se dictan normas en materia financiera, de seguros, del mercado de valores y otras disposiciones, en Gaceta del Congreso, No. 138 de 2008. Para mayor claridad en el tema del sistema financiero, véase Durán Vinazco, Ricardo; Proyect Finance y emisión de títulos; Universidad Santo Tomás; páginas 49 y siguientes. Así mismo véase Pamplona Hernández, Armando; el derecho del mercado financiero, en De la Cuesta Rute y Valpuesta Gastaminza; contratos mercantiles Tomo III. Editorial Bosch.
} 
financiera, conoce en mejor forma el mercado, los riesgos y el régimen jurídico de la operación. Adicionalmente, en su condición de proveedor de servicios en forma masiva, la institución financiera establece sus relaciones jurídicas a través de esquemas contractuales previamente elaborados, no sujetos a discusión o modificación. Generalmente el cliente sólo puede aceptar el producto o servicio en los términos o condiciones en que es ofrecido o rechazarlo".

La actividad financiera está en la obligación de cumplir con una función social, en virtud del principio constitucional de "primacía del interés general sobre el interés particular" (Articulo 1 Constitución Política de 1991). Ello indica que su libertad para auto regularse es restringida. La Corte Constitucional, en sentencia C-995 de 2000 manifestó "(...) la actividad de intermediación financiera ${ }^{3}$, en el estado social de derecho, supone responsabilidades; y tiene una función social que implica obligaciones, lo que sencillamente significa que su libertad, lejos de ser absoluta o de hallarse exenta de controles e intervenciones, está marcadamente restringida y dirigida por el Estado".

\footnotetext{
${ }^{3}$ La actividad financiera, específicamente la de intermediación financiera, deben entenderse como aquellas operaciones realizadas por entidades autorizadas de acuerdo al Decreto 663 de 1993 -Estatuto Orgánico del Sistema Financierodentro del sistema financiero. Los sistemas financieros "están conformados por las autoridades que los gobiernan, los regulan, y supervisan y las instituciones que operan en los mercados del ahorro, la inversión, el crédito y los servicios auxiliares de los mismos.

Teniendo en cuenta que la actividad económica que están llamadas a emprender las instituciones financieras, se puede desenvolver dentro de modelos o esquemas de muy diversa configuración, que particularmente se caracterizan por el ámbito o extensión del mercado en que las instituciones pueden operar, corresponde a las autoridades reguladoras organizar el sistema con arreglo al modelo escogido y definir el marco regulatorio dentro del cual pueden operar las entidades y la forma en que deben hacerlo". Véase, CONGRESO DE LA REPÚBLICA, Ponencia para primer debate al Proyecto de ley 282 de 2008 Cámara, 286 de 2008 Senado: por la cual se dictan normas en materia financiera, de seguros, del mercado de valores y otras disposiciones, en Gaceta del Congreso, No. 341 de 2008
} 
Al ser la actividad financiera de interés público, el artículo 335 consagra la facultad del Estado de intervenir en la dinámica de las entidades tanto públicas como privadas que desarrollan esta actividad, lo que implica que su desarrollo no es del todo libre, sino que, por el contrario, está sometida a controles estatales. Está posibilidad de delimitar a los bancos en sus actividades se da con el fin de que no se vulneren los derechos de los ciudadanos que acceden a estos.

Es importante mencionar que, además de ser una actividad de interés público (por tenerse en cuenta como motor de la economía, y por que con esta se hace referencia al principio de que prima el interés general sobre el particular), la Corte Constitucional ha entendido que a través de la actividad financiera se presta un servicio público. Aunque constitucionalmente, el Art. 335 de la Constitución determina que la actividad financiera es de interés público, no existe una norma expresa que establezca que las entidades bancarias presten un servicio público. Por ello, la Corte Constitucional, en sentencia de Tutela T-520 de 2003, acudiendo a criterios históricos y jurisprudenciales, otorgó a la actividad financiera el carácter de servicio público.

La Corte Constitucional en sentencia T-520 de 2003, acudiendo a lo dicho por la Corte Suprema de Justicia en sentencia de 1970, sostuvo que un servicio público es "... toda actividad tendiente a satisfacer una necesidad de carácter general, en forma continua y obligatoria, según las ordenaciones del derecho público, bien sea 
que su prestación esté a cargo del Estado directamente o de concesionarios 0 administradores delegados, o a cargo de simples personas privadas".

Definido el servicio público, la Corte Constitucional cuestiona si la actividad bancaria constituye o no servicio público. El primer argumento usado por la Corte Constitucional (Sentencia T-520 de 2003) es de carácter histórico, al recordar que en 1953 mediante Decreto $1^{\circ}$ del mismo año se dijo expresamente "[d]eclárense de servicio público las actividades de industria bancaria, ya sean realizadas por el Estado, directa o indirectamente o por los particulares". Este primer argumento, sin embargo, sólo sirvió como nota aclaratoria, pues mediante la Ley 48 de 1968, el Art. $1^{\circ}$ del Decreto $1^{\circ}$ de 1953 fue derogado. Posteriormente, la Corte Constitucional acude a la evolución jurisprudencial de la Corte Suprema de Justicia y de la misma Corte Constitucional.

Para la Corte Suprema de Justicia (Sala Plena, Sentencia 06.06.197, citada por Corte Constitucional, Sentencia T-520 de 2003), "La actividad bancaria, tanto la oficial como la privada, es una actividad de servicio público. A falta de una definición legal, ha dicho la Corte, se debe estar a la doctrina, a la jurisprudencia y a los preceptos del derecho positivo relacionados con la materia. Para la doctrina y la jurisprudencia, servicio público es toda actividad encaminada a satisfacer una necesidad de carácter general, en forma continua y obligatoria, según las ordenaciones del derecho público, bien sea que su prestación esté a cargo del Estado directamente o de concesionarios o administradores delegados, o a cargo 
de simples personas privadas". En contra de este pronunciamiento, podría decirse que la Sentencia fue profería con anterioridad a la expedición de la Constitución Política de 1991, sin embargo, la Corte Suprema de Justicia volvió a calificar la actividad bancaria como servicio público en 1997. Según la Corte Suprema de Justicia (Sala Plena, Sentencia 06.06.197, citada por Corte Constitucional, Sentencia T-520 de 2003) "[t]ambién se catalogaron como actividades de servicio público la de la industria bancaria; la de la banca central, adjetivada adicionalmente de esencial; la de los servicios públicos domiciliarios, y la de seguridad social en salud y en pensiones en cuanto estén vinculadas con el reconocimiento y su pago, también señaladas como esenciales".

Finalmente, la Corte Constitucional acude a dos Sentencias de la misma, para afirmar el carácter de servicio público de la actividad financiera. En Sentencia T443 de 1992 "la Corte sostuvo que la actividad bancaria constituye un servicio público, no sólo porque cuenta con los atributos propios de dicha actividad, también porque así ha sido clasificada por el derecho positivo, y porque este carácter ha sido reconocido sistemáticamente por la jurisprudencia. Por tales motivos, con fundamento en el carácter de servicio público de la actividad financiera, ordenó levantar la suspensión de las resoluciones expedidas por el Ministerio de Trabajo". Asimismo, la Corte Constitucional en Sentencia SU- 157 de 1999 sostuvo que “(...) las personas jurídicas que desarrollan la actividad bancaria, independientemente de su naturaleza pública, privada o mixta, actúan en ejercicio de una autorización del Estado para cumplir uno de sus fines, que es 
el de la prestación de los servicios públicos, por lo cual gozan de algunas prerrogativas propias de la actividad, pero igualmente se obligan a cumplir condiciones mínimas de derechos de los usuarios. En consecuencia, la acción de tutela en contra de quiénes prestan un servicio público es formalmente procedente, por lo que la Corte Constitucional (Sentencia T-520 de 2003) entra a conocer de fondo el asunto sub iudice". Igualmente la Corte Constitucional, en sentencia del T- 312 de 2010, manifestó que “(..) pese a que no existe norma que de manera expresa así lo determine, en el derecho Colombiano es claro que la actividad bancaria es un servicio público, pues sus nítidas características así lo determinan. En efecto, la importancia de la labor que desempeñan para una comunidad económicamente organizada en el sistema de mercado, el interés comunitario que le es implícito, o interés público de la actividad y la necesidad de permanencia, continuidad, regularidad y generalidad de su acción, indican que la actividad bancaria es indispensablemente un servicio público".

Así la Corte Constitucional le dio a la actividad financiera el carácter de servicio público. Sin importar la naturaleza de la actividad que se está desarrollando, es decir, si es pública o privada, dichas actividades no riñen con el concepto de servicio público. Al ser servicio público son inherentes a la finalidad social del Estado, y por tanto constituyen un instrumento necesario para el desarrollo de los valores y principios constitucionales. Para la Corte Constitucional (Sentencia T520 de 2003) “(...) no les asiste razón a los jueces de instancia -la Sala Civil del 
Tribunal Superior de Bogotá y de la Corte Suprema de Justicia -, quiénes afirmaron que la actividad financiera (o bancaria) no constituye un servicio público, en contra de lo dispuesto por el ordenamiento positivo y por la jurisprudencia reiterada de todas las altas cortes del país. Por lo tanto, en relación con la legitimación por pasiva, la tutela en contra del BBVA - Banco Ganadero y del Banco de Bogotá resulta procedente".

La Corte Suprema de Justicia trató el tema de la irrelevancia que presenta que el desarrollo de la actividad en manos de una entidad de carácter público o privado, ya que sin importar quién la ejecuta, la actividad tiene carácter de servicio público. En Sentencia de 12/VI/69 (Sala de Casación Civil, M.P. Hernán Toro Agudelo) la Corte Suprema de Justicia manifestó que "la jurisprudencia reiterada de la Corte Suprema ha reconocido la calidad de servicio público que tiene la actividad financiera, sin importar el carácter público o privado del órgano que la lleve a cabo...".

La contratación bancaria, entendida ésta como aquel acuerdo de voluntades tendiente a crear, modificar, regular o extinguir una relación jurídica bancaria que busca que el banco realice la actividad de captar dinero o fondos del público (DIEZ ESTELLA, fernandodiezestella.com: 15.08.10), se encuentra inmersa dentro de la actividad financiera. La Superintendencia Financiera de Colombia indica que para desarrollarla "...los únicos tipos de entidades financieras autorizados para ello serían los establecimientos de crédito, v. gr. bancos, corporaciones financieras, 
compañías de financiamiento comercial y cooperativas financieras vigiladas por esta Superintendencia..." (Concepto 2006056363-002 del 8 de noviembre de 2006).

Si la actividad financiera es de interés público y es un servicio público, la contratación bancaria, por ser parte de esta, también lo es, y por esto el Estado debe regularla, es decir, debe verificar su buen funcionamiento, a través de entidades administrativas, como la Superintendencia Financiera, quién interviene mediante actos administrativos tales como conceptos, o por medio de las leyes que expide el Congreso de la República que reglamentan dicha actividad.

Lo anterior es relevante porque si el Estado la regula, el fin último de éste (en el aspecto de la contratación bancaria), es que no sean afectados los intereses de la comunidad, manifestados en el caso concreto de la contratación bancaria en los usuarios de dichas entidades. Por tanto el Estado debe intervenir en la actividad financiera de manera activa, evitando que se generen asimetrías entre el Banco y el usuario del servicio que es el ciudadano común.

El hecho de que la actividad financiera sea objeto de interés público significa que el Estado debe estar atento a su regulación, es decir, las entidades financieras no tienen la posibilidad de ejercer su libertad económica plenamente, sino que son "susceptibles de una rígida intervención estatal dirigida a ordenarla, imponer las 
condiciones en las cuales debe prestarse, entre otras" (RODRIGUEZ AZUERO, 2009: Pág. 114).

Si la actividad bancaria, manifestada concretatmete en el contrato bancario, es considerada de vital importancia para el desarrollo económico y el cumplimiento de los fines del Estado, siendo así de interés público, el cuál, en términos de la Corte Constitucional, se concreta mediante la prestación de un servicio público, el Estado se encuentra, por disposición del Art. 335 de la Constitución Política, facultado para intervenir en la producción de los contratos realizados por las entidades bancarias. Sin embargo, la intervención del Estado se puede dar sólo en virtud del cumplimiento de las normas y criterios constitucionales, reflejados en la Cláusula General de Competencia.

\section{B. Intervencionismo Estatal en "pro" del Interés Público}

La capacidad de intervención estatal se encuentra fundamentada en la Cláusula General de Competencia (CGC), definida por la Corte Constitucional en sentencia C- 337/93 como "El principio según el cual a los particulares se confiere un amplio margen de iniciativa, al paso que los servidores públicos deben ceñirse estrictamente a lo autorizado por la Constitución y la ley, está recogido en el texto constitucional en su artículo 6) (...)". 
Un panorama de la cláusula general de competencia (desde el punto económico) podría plantearse así. Cuando el Estado interviene, debe responderse tres preguntas básicas, a saber, "qué", "quién" y "cómo". Respecto al "qué", responde a qué hace la CGC. En cabeza de ésta, está la dirección de la economía desde tres ámbitos macro (regula la política fiscal y la política monetaria), financiero (aquí se incluye el artículo 335 de la Constitución), y micro (respecto a las microempresas que tienen libertad económica). En cuanto a "el quién" esto se revisa desde el artículo 113 de la Constitución que hace referencia a las ramas del poder público ejecutivo, legislativo y judicial. Todas estas trabajan de manera independiente pero armónica. Para el "cómo" es necesario revisar los artículos 150, y 189 de la Constitución Política.

La interpretación que se le ha dado a la cláusula general de competencia se fundamenta en varios artículos constitucionales como el 4, 5, 334, 335, 336. En cuanto al "quién" y al "cómo" los artículos son 11, 150, 189, de la Constitución, expresan que es función del Congreso de la República hacer leyes generales y abstractas.

Dicha CGC presenta unos límites que comprenden, como lo ha expresado la Corte Constitucional, los establecidos en el artículo 121 de la Constitución -entre otros-, que indica asuntos que regulan determinados entes estatales. 
De igual manera, otro limite a la CGC es la obligación que tiene el legislador de respetar las normas, principios y derechos constitucionales, ya que al transgredir alguno de estos, el Estado debe intervenir y limitar la actuación del órgano que lo esté haciendo (Corte Constitucional, Sentencia C-473/97).

En derecho existe el principio según el cual todo lo que no está prohibido en la Constitución está permitido para el Congreso. Este principio podría ser un límite a la CGC, debido a que se puede aplicar a los servidores públicos con el fin de que no abusen de sus funciones cuando ocupan cargos públicos. Esto quiere decir que respecto a los particulares, a estos se les aplica que a los aspectos que no tienen restricciones en la Constitución, ley, costumbres y otras regla que regulen la conducta, pueden los particulares mismos "gobernar" o generar sus normas de conducta, ya que no van a ir en contraposición con las normas que regulan su actuación en general, logrando así aplicar que lo que no está prohibido está permitido para los particulares.

No obstante, para los funcionarios que ejercen cargos públicos, y que le dan "vida" a la CGC no es así. Ellos no pueden simplemente auto regularse en los asuntos que no están claramente estipulados en la norma, esto es un límite a la CGC ya que no conlleva a que un tema que no esté regulado pueda ser reglado por ellos, por el contrario hay otros mecanismos para regularlo como por ejemplo la analogía. 
Recientemente la Corte Constitucional en el año 2000 manifestó que el Congreso de la Republica es el titular de la cláusula general de competencia por ser una “institución jurídica de naturaleza política, pluralista, representativa y electiva". En esta ocasión la Corte reitero que las facultades del Congreso no son absolutas y que tiene límites como por ejemplo el del artículo 121 de la Constitución Política (Corte Constitucional, Sentencia C - 1648 de 2000).

Según la CGC, para que el Estado pueda intervenir, es necesaria la existencia de una legitimación legal (Reserva Legal) para que, o la administración ejecute acciones de intervención, o la jurisdicción delimite la libertad contractual, mediante la interpretación. Esa legitimación legal es de tipo preventivo, ya que el interés del legislador es regular las materias antes de que surja el conflicto.

\section{Caso Concreto: Relación Banco - Consumidor Financiero}

En cuanto a la relación entre el consumidor financiero y banco, no se podía hablar de regulaciones sistemáticas expresas. Desde la perspectiva legal, la tendencia se inclinaba hacia una consideración de los contratantes en un plano de igualdad, es decir, Banco y usuario no tenían trato indiferenciado ${ }^{4}$.

\footnotetext{
${ }^{4}$ La única excepción posible podría encontrarse en la ley 795 de 2003, que en sus Arts. 23 y siguientes, establece medidas de protección al consumidor, tales como la obligación de brindar información adecuada. Sin embargo, esta ley no constituye en sí misma una regulación sistemática de protección al consumidor. Para un análisis sobre el tema véase congreso de la república, Proyecto de Ley 282 Cámara, en Gaceta del Congreso No. 138 de 2008.
} 
En Colombia la regulación de la actividad financiera no se ha dado desde un plano consumidor-banco, sino que se ha desarrollado a través del concepto de las instituciones financieras. Antes de la Constitución de 1991, la ley 45 de 1990 regulaba las normas en materia de intermediación financiera, actividad aseguradora, y concedía algunas facultades, esta ley fue modificada por la ley 510 de 1999. La Ley 1730 de 1991 habló de las instituciones financieras como establecimientos de crédito, cuya función principal consiste hoy día, en captar moneda, para colocarla en el mercado a través de operaciones de activas de crédito (MARTINEZ NEIRA, 1994: Pág. 7).

El estatuto orgánico del sistema financiero (DECRETO 663 DE 1993), se refirió a temas como la descripción de las entidades sometidas a la vigilancia y control de la Superintendencia bancaria, funciones de las instituciones, procedimientos, pero nada concreto respecto al consumidor bancario.

La principal actuación estatal durante los primeros años de la vigencia de la Constitución del 91 se ve en la jurisdicción, especialmente la constitucional, a través de la acción de tutela, regulada en el Artículo 86 constitucional. Respecto al tema de la contratación bancaria, en las demandas por afectación de Derechos Fundamentales, las acciones han tenido como demandados a bancos y compañías de seguros. 
El 3 de agosto de 1999 se expidió la LEY 510 DE 1999, relativa a disposiciones en relación con el sistema financiero y asegurador, el mercado público de valores, y las Superintendencias Bancaria y de Valores (Hoy Superintendencia Financiera). Esta ley no se refiere expresamente al tema de la protección al consumidor bancario. Con el Decreto 018 de 2007 se modificó el estatuto orgánico del sistema financiero, cambiando las modalidades de crédito, pero nada relativo al consumidor.

En sede jurisdiccional ha tomado un valor especial la interpretación judicial, entendida como el otorgamiento de facultades especiales a los jueces para determinar cómo han de entenderse las cláusulas contractuales o para establecer la existencia de cláusulas abusivas que son, generalmente, desfavorables para una de las partes. Para la relación entre Banco y Consumidor, quién impone este tipo de cláusulas es el banco y el afectado el consumidor financiero.

Por medio de la interpretación, el juez ha establecido juicios que pueden ser distintos a los pensados por las partes. Jorge Suescún Melo, indica que dicha "intromisión" de los jueces en la autonomía de la voluntad de las partes que configuraron el contrato, no es tan positiva, ya que llegaría al punto en que se configurarían "contratos judiciales", es decir, el origen de la voluntad de los contratantes no sería esta misma, sino la percepción del juez sobre el caso concreto. 
Sin embargo, debe tenerse en cuenta que el juez, al interpretar el contrato, deber hacerlo a favor de la parte débil del contrato si existe una desigualad evidente, y si ésta contribuyó para que la relación contractual no se llevara a término; esto en miras a la protección de Derechos y Principios constitucionales. Sin ésta intervención o intromisión (en términos de Suescún), en la relación consumidorbanco podrían presentarse fuertes situaciones de desigualdad, ya que en el momento en que el juez deba a causa de injusticias fallar a favor de la parte débil y no lo haga, va a generar un desequilibrio en la relación contractual aun mayor del que estaba antes de que fallara.

En el año 2002 la Corte Constitucional dijo expresamente que las entidades bancarias tienen una posición dominante frente a los usuarios del sistema financiero, ya que estas son las que establecen los requisitos de créditos, tasas de interés, entre otras operaciones que realizan los bancos. Indicó la Corte que las entidades financieras son depositarias de la confianza pública por el servicio que prestan, y que sus actuaciones cuentan con veracidad por parte de los clientes (Corte Constitucional, Sentencia T-1085 de 2002).

En el mismo sentido esta Corte Constitucional se pronunció en sentencia T-661 de 2001:

“(...) al tener los bancos atribuciones que los colocan en una posición de preeminencia desde la cual pueden con sus acciones y omisiones desconocer o amenazar derechos fundamentales de las personas. 
Independientemente de su naturaleza pública, privada o mixta los bancos actúan con una autorización del Estado para prestar un servicio público por ello, los usuarios están facultados para utilizar los mecanismos de protección que garanticen sus derechos".

Asimismo la Corte Constitucional aclaró que por tener las entidades bancarias una posición dominante frente a los usuarios del sistema financiero, se le impone al Estado la obligación de controlar sus actividades para de esta manera evitar cualquier tipo de abuso (Corte Constitucional, Sentencia T-173/07).

El más reciente fallo de la Corte Constitucional respecto a este tema fue la Sentencia T-129 de 2010, en donde se pronunció acerca de la violación de los derechos constitucionales por cobrar los bancos deudas muy antiguas de las cuales no tenía prueba alguna. Esta sentencia es importante porque manifiesta que el pago voluntario de una deuda que se cree tener no exonera al banco de demostrar la veracidad de la misma.

Posteriormente se dio un movimiento hacia la producción de normativa administrativa y legal tal y como lo es la ley 1328 de2009, "por la cual se dictan normas en materia financiera, de seguros, del mercado de valores y otras disposiciones."; a partir de esta ley y de manera expresa, se da regulación para proteger al consumidor bancario, cuestión que anteriormente no se había discutido propiamente en la ley. 
Se puede destacar, que pese a que la CGC establece un orden de lo legal a lo jurisdiccional, hablamos de una "intervención inversa", es decir, desde lo jurisdiccional a lo legal. La actuación estatal respecto a los contratos bancarios se ha realizado de forma inversa. Prueba de ello es lo que se va a desarrollar a continuación.

Lo que sucede es que la cláusula general de competencia, establece generalmente que el Estado intervendrá mediante tres agentes en el siguiente orden: 1) el legislador; 2) la administración; 3) el juez; sin embargo en el tema en cuestión se da de manera inversa.

El juez, como aquel encargado de resolver conflictos y administrar justicia, se encuentra con una doble limitación al momento de realizar sus actividades relativas a esto:

1. Respecto a su iniciativa en el sentido de qué el no puede intervenir en las relaciones jurídicas, hasta tanto no se presente un conflicto en el que intervengan las partes. De hecho no es necesario únicamente que se presente el conflicto, sino que las partes acudan a él para que las ayude a solucionar dicho conflicto.

2. Con relación a su decisión, ya que ésta solo puede ceñirse al problema que le plantean las partes, y además la decisión debe darse con base en las 
fuentes que le proporciona el sistema jurídico, en el sentido de que las fuentes son básicamente tres.

a. Constitucional: Esta se desarrolla a través de la Constitución, es decir el Juez debe mirar los principios y normas constitucionales para resolver el conflicto.

b. Legislación: Es decir, las leyes que se refieren al tema especifico sobre el cual el Juez debe actuar.

c. Administración: Se refiere a los actos administrativos que para el caso en concreto expide la Superintendencia Financiera.

La dinámica frente al tema de la contratación bancaria funcionaba así: El Juez no tenía regulación expresa acerca de la contratación bancaria respecto a la protección del consumidor, por lo que para solucionar los conflictos que llegaban a él debía de manera invertida remitirse a la Constitución, lo cual es una fuente de derecho demasiado general, por lo que debía limitarse a aplicar principios constitucionales. Se dice que de manera invertida pues el Juez en caso de conflicto debería remitirse a norma general como la Constitución y no especial como la ley misma.

Diríamos que el orden lógico sería una intervención legislativa, ejecutiva y judicial, sin embargo se ha realizado de forma inversa ya que desde 1991 con la nueva Constitución, surgió la tutela como mecanismo de protección de derechos fundamentales como mencionaba anteriormente, y con esto surgió el interrogante 
acerca de los derechos fundamentales. Gracias a la tutela se logró que las personas que se sentían vulneradas en una relación contractual banco - usuario, asistieran a la protección de sus derechos a través de la tutela y además, se obtuvo en parte la protección al consumidor bancario.

El Juez acudía a la Constitución, y por ser esta norma de carácter general, lo que se daba era que no estaba limitada su actividad pues la regulación en el tema era escasa, por lo que el Juez estaba facultado para solucionar los conflictos de manera amplia, y así entonces no se lograba que las situaciones se solucionaran de raíz, pero como decía antes, gracias a la ley 1328 este panorama cambió, ya que se reguló expresamente la protección al consumidor bancario.

\section{Concepto y estado actual de la Autonomía Privada de la Voluntad}

\section{A. La Autonomía de la Voluntad desde la Doctrina y Jurisprudencia Colombiana}

En cuanto a la definición de APV, hay que tener claro que no es algo estipulado taxativamente en la ley, sino que ha sido fruto de la interpretación de las normas del Código Civil y por ello cada autor tiene su noción acerca del tema (DE BUEN LOZANO, 1986: ). 
Pese a las distintas definiciones de dicho principio, ${ }^{5}$ se entenderá en este escrito la APV como el principio que faculta a una persona para auto regularse y auto determinarse en su actuar y en su proceder frente a determinadas situaciones, especialmente en materia contractual. Lo anterior se refleja en autores como Suescún Melo, para quien es "la elección del particular de contratar o no contratar; escoger la persona del contratante; determinar el tipo de contrato que se va a celebrar y; definir el contenido y régimen del acto jurídico" (SUESCUN MELO, 2009: Pág. 3).

López Cabana confirma lo anterior refiriéndose a las características de la APV. Las enuncia de la siguiente forma:

1. Se expresa en la autodeterminación del sujeto de aceptar o rechazar una disposición.

2. Las personas son libres para contratar o abstenerse de hacerlo.

3. Le asiste la potestad de reglamentar el acto propio para constituir, modificar o extinguir relaciones jurídicas.

4. Se tiene la facultad de elegir la forma de contrato, modificarlo, transmitir la posición contractual, ponerle fin, entre otras (ALTERINI; LÓPEZ C., 1989: Págs. 36 y s.).

\footnotetext{
${ }^{5}$ La APV para Monroy Cabra es entendida como "un poder o energía creadora de la voluntad: El poder que tendría la voluntad (del promitente) para crear la obligación, el vinculo o relación jurídica (José Ferralis Vilella)" (MONROY CABRA, Marco Gerardo. ¿ESTA EN CRISIS EL PRINCIPIO DE LA AUTONOMIA DE LA VOLUNTAD? Revista de la Academia Colombiana de jurisprudencia. Julio-Diciembre. 1980 Pág. 102.). William Namen Vargas señala que la APV "se concentra en la posibilidad reconocida al sujeto para disponer de sus derechos e intereses. La autonomía es autogobierno, auto regulación, poder de darse la ley uno mismo, actuar, obrar, crear, disciplinar u orientar la propia conducta, disponer de derechos e intereses. En sentido abstracto, la noción comprende toda posibilidad admisible de autodeterminación, incluyendo la aptitud activa del sujeto, el poder y el derecho subjetivo. Potestad de darse normas por sí y para sí." (NAMEN VARGAS, William. LA LIBERTAD CONTRACTUAL: NEGOCÍO JURIDICO Y CONTRATO. Consejo Superior de la Judicatura. Revista Judicial. Diciembre 2009.)
} 
El Estado del Siglo XIX aplicaba dos pilares: Libertad e igualdad. Sobre estos, se fundamentan los 4 principios del derecho privado, dentro de los cuales se encontraba la APV. ${ }^{6}$ (SUESCUN MELO, 2009: Pág. 3)

La libertad se entendía como la capacidad que tenía la persona para tomar sus decisiones sin influencia de un tercero. La igualdad era aquel reconocimiento y trato indiscriminado que proporcionaba la ley a los particulares, es decir, que para administrarlos no eran tenidos en cuenta factores como el económico o la posición social.

Sin embargo, estas formas de ver o entender estos pilares entraron en cuestionamiento a finales del Siglo XIX y comienzos del Siglo XX. Por una parte, las distintas clases económicas -junto con los avances de la revolución industrialgozaban de cierta potestad fáctica de imposición de reglas. Asimismo, dicha imposición restringía la libertad de autorregulación y dejaba a sus contrapartes en una posición de desigualdad.

Debido a esto el Estado se vio en la necesidad de cambiar algunos paradigmas como por ejemplo su pasividad en temas como la contratación bancaria y la protección del consumidor.

\footnotetext{
${ }^{6}$ Los otros tres principios son el consensualismo, el pacta sunt servanda y el principio de la ejecución de buena fe de los contratos.
} 
Hoy día el Estado tiene la posibilidad de limitar las actuaciones e intercambios comerciales de los particulares, convirtiéndose así en intervencionista, sin que esto implique que las personas no puedan hacer uso absoluto de su APV.

En Colombia la Corte Constitucional y la Corte Suprema de Justicia se han referido al tema de la APV en reiteradas ocasiones. En ambas jurisprudencias, tanto en la privada como en la constitucional, se ha definido el principio de la APV. Para la Corte Constitucional se entiende que la APV consiste en la delegación que el legislador hace en los particulares de la atribución o poder que tienen de regular las relaciones sociales. Le da mayor libertad a las transacciones entre particulares y en general en todos sus actos jurídicos de contenido económico (T338 de 1993)

La Corte Constitucional en la sentencia T- 338 de 1993 menciona que "La autonomía de la voluntad privada consiste en el reconocimiento más o menos amplio de la eficacia jurídica de ciertos actos o manifestaciones de voluntad de los particulares.

Se refiere la Corte igualmente a la libertad de contratación que se deriva de la Constitución, que implica unas limitaciones de base legal y garantiza unas relaciones justas y libres entre los particulares. (Sentencia No. T-240/93). 
La APV como concepto ha sido desarrollada por la Corte Suprema de Justicia desde 1936. Sin embargo, podemos decir que en las relaciones bancarias el análisis inicia en 1974. La noción de contrato en este momento está enfocada a que dos personas, en un mismo pie de igualdad jurídica, exponen y discuten en un libre debate sus recíprocas pretensiones, se hacen concesiones mutuas y si ajustan sus voluntades acaban por celebrar un acuerdo cuyos términos han sido pensados, y constituyen la expresión de sus propósitos.

En 1980, estipula claramente la definición de APV, indicando inicialmente que en el derecho positivo colombiano es más relevante la voluntad de los contratantes que las leyes mismas al momento de regular el contrato, teniendo en cuenta el orden público y las buenas costumbres. La APV es como una convención que no puede desconocerse por su naturaleza contractual, pues mientras el cliente pueda rechazar la oferta, su voluntad actúa a tal punto que al acogerla presta libremente su consentimiento.

En 1994 se habla de APV como un conjunto de facultades con que cuentan las personas. Estas se condensan en la de celebrar un determinado negocio jurídico o dejar de hacerlo, en la de elegir con quién realizarlo y en la de estipular las cláusulas llamadas a regular la relación así creada.

Se regulan en este caso las conductas abusivas que en cuanto ocasionen agravio a intereses legítimos no amparados por una prerrogativa especifica, dan lugar a 
que el damnificado, aun encontrándose vinculado por el negocio y por fuerza precisamente de las consecuencias que para el acarrea la eficacia que de este último es propia, pueda exigir la correspondiente indemnización.

La Corte Suprema de Justicia (CSJ) en sentencia de 6 de julio de 2009, expresó algo relacionado con la autonomía con que cuenta el juzgador, y eso es que si el juez tras examinar y aplicar las diversas reglas de hermenéutica establecidas en la ley, opta por uno de los varios sentidos plausibles de una determinada estipulación contractual, esa elección, en sí misma considerada, no puede ser enjuiciada en la Corte, so pretexto de una construcción más elaborada que pueda presentar el demandante en casación, en la medida en que en esa hipótesis, la decisión judicial no proviene de un error evidente de hecho en la apreciación de las pruebas, sino que es el resultado del ejercicio de la discreta autonomía con que cuenta el juzgador de instancia para la interpretación del contrato.

Ahora se analizará una cuestión y es la siguiente. La CSJ se ha encargado de analizar si la APV se ha utilizado en los contratos de adhesión, ya que estos son los que utilizan los bancos en sus operaciones. Así en el año 74 la CSJ los ha entendido desde dos ópticas y estas son:

-Teoría reglamentaria: La fuente creadora de obligaciones se descompone en la emisión de una voluntad reglamentaria y en la adhesión a ella de otra voluntad, la 
que no contribuye a la formación del acto cuyo efecto no es otro que llenar un requisito secundario.

-Teoría contractual de los actos de adhesión: Los contratos de adhesión tienen real y efectivamente el carácter de verdaderos contratos que merecen una interpretación particular, pero contratos al fin porque el individuo conserva la voluntad de contratar o no, y si lo hace es porque quiere. El individuo es libre de no comprometerse pero una vez comprometido, está obligado a respetar su decisión; es el efecto del contrato. Se deben distinguir las cláusulas esenciales de las cláusulas accesorias.

\section{B. La Autonomía de la Voluntad en la Relación Banco-Consumidor Financiero}

En el caso de la contratación bancaria, el Banco tiene gran libertad para diseñar los contratos, lo que lo pone en una situación ventajosa frente al usuario. Por ello es necesario para el Estado intervenir en su actividad, y delimitar su autonomía, a tal punto que no haya desprotección al "débil" en la relación contractual.

Sin embargo, con todo y la intervención de Estado, dicha APV del banco no se ve del todo restringida, desde que se le deje realizar la contratación en masa, que se desarrollar a través de contratos de adhesión o contratos estándar. 
Dichos contratos le permiten al Banco una posición dominante frente al usuario, debido a que aquel pone las condiciones del contrato, y este último solo tiene la opción de "firmar" o no el contrato, lo que lleva a que no se puedan negociar las cláusulas contractuales, siendo así el banco el único que manda en la relación contractual.

Suescún Melo indica que los contratos de adhesión se dan cuando una parte debe plegarse a los términos y condiciones que le impone la otra sin negociación, ni modificación (SUESCUN MELO, 2005, Págs. 6 y ss.).

Los elementos del contrato de adhesión según este son:

1. Imposición de unas condiciones por una de las partes.

2. Papel pasivo de la otra parte.

3. Un formato tipo.

Los contratos de adhesión se dieron a raíz de que las operaciones bancarias se realizan en masa, razón por la cual a los bancos les resultaba complicado que cada vez que fueran a realizar un contrato, hacer una forma diferente para cada uno de ellos. Por esto se buscó uniformar y estandarizar estos contratos, lo que llevo a que se denominen contratos tipos.

La Superintendencia Financiera, en concepto del 26 de Febrero de 2007, precisó que el contrato de adhesión es definido por la doctrina como aquel en que "las 
cláusulas son dispuestas por uno de los contratantes de manera que la contraparte no pueda modificarlas ni hacer cosa distinta que aceptarlas o rechazarlas. En este tipo de negocios la parte que aprueba el texto de las cláusulas redactadas por la otra no interviene en la formación del contenido contractual...".

Lo anterior nos lleva al punto de que la autonomía del contratante que no realiza el contrato, se ve limitada a aceptar o rechazar la oferta, lo cual de alguna manera restringe su posibilidad de negociar las condiciones en que se va a desarrollar el negocio jurídico. Esto estaría un poco en contra de los principios de los que se hablaba en el siglo XIX, y que aun hoy se practican en el Estado de derecho, específicamente la libertad e igualdad, vistas desde la perspectiva contractual.

Los contratos de adhesión para Rodríguez Azuero surgen como una excepción a los que siguen el principio según el cual la concurrencia de voluntades está destinada a producir efectos jurídicos, y permiten una amplia discusión y detenido análisis respecto de las cláusulas, términos, objeto, consecuencias, entre otros. Para este autor, estos contratos surgen gracias a la contratación en masa que se da en la vida moderna (RODRÍGUEZ AZUERO, 2009: Págs. 114 y ss). 


\section{Estado Actual de la Autonomía de la Voluntad}

En Colombia los Arts. 16 y 333 de la Constitución Política enuncian el tema del libre desarrollo de la personalidad que se traduce en la autonomía de la libertad privada contractual, y en la libertad económica. Esto da cabida a que con la APV ya no es necesaria la influencia de la ley, sino que por el contrario con el solo acuerdo de voluntades en el contrato, ya puede llegar a ser válido.

La C- 993 de 2006, explica que el Art. 16 de la Constitución se "traduce en la facultad de las personas para auto regular su conducta en la vida social, reconocida por el ordenamiento jurídico, con sujeción a los límites impuestos por éste, y que se denomina autonomía personal. Una de dichas libertades es la económica o libertad de empresa, que los regímenes democráticos someten al límite del bien común, en armonía con el principio de la prevalencia del interés

general (Arts. 333 y $2^{\circ}$ C. Pol.), de la cual emana la libertad de contratación, es decir, la libertad de celebrar acuerdos con otras personas, con efectos vinculantes, para el intercambio de bienes y servicios o el desarrollo de actividades de cooperación y la satisfacción de las necesidades. Esta modalidad de la autonomía del individuo se ha denominado autonomía de la voluntad privada (APV) en el campo del Derecho Privado, esto es, en la rama del Derecho que regula las relaciones entre los particulares, en un plano de coordinación o paridad". 
Esto es importante ya que nos aclara que aunque el principio de la APV, no se encuentra estipulado como tal en la Constitución, no quiere decir que no se tenga en cuenta al momento de regular las relaciones contractuales entre los particulares.

Hoy día ahí actividades de interés público que están restringidas por el mercado y por el concepto de confianza que se maneja en la contratación bancaria. La restricción limita en algún sentido el modo de actuación de los bancos debido a la intervención estatal. Dicha intervención se manifiesta en la forma como el Estado le indica a los bancos la manera de contratar, lo que implica que la APV de estos, está limitada y restringida.

El principio de APV se da en unos términos de igualdad material que no los da el mercado, ni el usuario mismo del sistema, sino que debe ser regulado por el Estado, a través de principios desde la actividad judicial.

Respecto a la actividad legislativa, lo que se establece es que debe existir una previsión y reacción respecto de las situaciones asimétricas a través de las normas, profiriendo así una ley especial que regula cada situación. En la contratación bancaria, es un ejemplo importante la ley 1328 de 2009 .

La ley al prevenir y reaccionar frente a las situaciones, lo que está haciendo es apuntando al interés público mencionado anteriormente, es decir, lo importante en 
este caso es saber si la Ley 1328 de 2009 está realizada en pro de los usuarios de la contratación bancaria, para eliminar un poco las diferencias que se presentan entre consumidor y productor del servicio.

La APV actualmente respecto a la relación Estado - Particular, debe entenderse en el sentido que este último tiene la facultad de regular sus relaciones contractuales siempre y cuando se someta a los límites que impone la ley que son el orden público y las buenas costumbres.

\section{El Contrato Bancario a la luz de la ley 1328 de 2009}

\section{A. Generalidades}

Para conocer cómo se regula la relación contractual es importante como primera medida revisar el concepto de derecho financiero, para llegar a la conclusión, de que el Banco es quién en la relación contractual puede llegar a acreditar la posición dominante.

Néstor Humberto Martínez indica que el derecho financiero es: "el conjunto de principios y normas que gobiernan la formación, el funcionamiento, la actividad y la liquidación ordenada de las instituciones que tienen por objeto la captación, el manejo, el aprovechamiento y la inversión de fondos provenientes del ahorro del 
público, así como el ofrecimiento de servicios auxiliares del crédito" (MARTíNEZ NEIRA, 1994: Pág. 3).

Otro concepto importante es el de contrato bancario. Rodríguez Azuero indica que son los acuerdos que se celebran entre el banco y su clientela nacidos de una relación cuyo objeto es una operación bancaria.

El banco tiene dos tipos de clientes. Uno de tipo empresarial y otro los clientes comunes del banco. Estos son clientes bancarios en tanto que son sujetos pasivos de ciertos deberes genéricos del banco, con prescindencia de la calidad y de la intensidad del contacto jurídico habido entre ellos. El cliente general o el consumidor y usuario bancario padecen, de una inferioridad relativa frente al contratante (BARBIE, 2002: Págs. 69 y s.).

Dicha inferioridad puede constituir la posibilidad de afectación negativa de Derechos de Consumidores, ya que si ellos no pueden negociar las condiciones de un contrato, especialmente bancario, parte de sus intereses no serán protegidos; asimismo, las instituciones bancarías se encontrarían en la facultad de establecer cargas excesivas a los consumidores financieros, tales como altas tasas de interés, requisitos exagerados, entre otros. El establecimiento de cargas excesivas por parte de las instituciones bancarias, además de constituir una posible afectación negativa de Derechos de Consumidores puede llegar a producir un comportamiento negativo en el mercado, debido a que, si los consumidores en 
general encuentran un alto grado de dificultad en el acceso a créditos bancarios, la confianza en el banco y en el ahorro disminuiría.

Teniendo en cuenta que la intervención del Estado en materia de protección al Consumidor bancario se ha dado de forma inversa -inicialmente a través de la acción jurisdiccional, pasando por la administrativa y llegando a la legislativa-, las consideraciones fundamentales en cuanto a la necesidad de protección se han dado en la Jurisprudencia de las Altas Cortes, especialmente en la Corte Constitucional. Para la Corte Constitucional (Sentencia C-749 de 2009), es necesario identificar dos momentos en la evolución de la participación y protección del Consumidor. El primer momento, denominado "preconstitucional" -antes de 1991-, "la relación entre los sujetos que concurren al circuito comercial de distribución de bienes y servicios (productores, comercializadores y consumidores) estaba basada en la reglas propias del liberalismo económico. Los consumidores, en su condición de adquirentes de los productos, estaban en un plano de igualdad de negociación con los oferentes de los mismos y, en caso de que se encontraran desequilibrios en su compraventa, bien por desigualdades ostensibles en el precio o en la calidad exigible de las mercaderías, tenían a su disposición herramientas propias del Derecho Civil para reparar el daño sufrido (...). Esto implicaba, como es obvio, la presunción que los productores, intermediarios y consumidores i) acceden al mercado en idénticas condiciones, ii) tienen a su disposición el mismo grado y calidad de la información y iii) poseen idénticas condiciones de acceso a la 
solución jurisdiccional de los conflictos que se susciten en esas relaciones de intercambio".

Sin embargo, esta realidad no es compatible con la entrada en vigencia de la Constitución Política de 1991, en la cual, se consagra la obligación de un reconocimiento de igualdad formal, que implica el entendimiento de situaciones asimétricas en el mercado, donde el consumidor no cuenta con las mismas condiciones que los demás agentes del mercado, especialmente los bancos. Es así, como la Corte Constitucional afirma que en Colombia se ha entrado en un segundo momento, que gira en torno a un criterio liberal como el preconstitucional. En términos de la Corte Constitucional (Sentencia C-749 de 2009) "el cambio cualitativo antes citado radica en el reconocimiento, por parte del Derecho Constitucional de las hondas desigualdades inmanentes al mercado y al consumo. De un lado, el avance de la ciencia y la tecnología en la sociedad contemporánea y, sobre todo, la especialización en los medios productivos, ocasiona grandes asimetrías de información entre los sujetos que concurren al intercambio de bienes y servicios. En efecto, los consumidores suelen carecer del conocimiento y experticia suficientes para discernir acerca de los aspectos técnicos que definen la calidad de los productos, incluso aquellos de consumo ordinario (...). Los consumidores en ese marco de información asimétrica y desigualdades fácticas con los comercializadores y productores, adoptan sus decisiones de adquisición de bienes y servicios basados, esencialmente, en relaciones de confianza (...). Estas condiciones fueron advertidas por el constituyente, quién consagró en el Art. 
78 de la Carta Política herramientas definidas, destinadas a proteger a los consumidores de las consecuencias del desequilibro sustancial antes explicado".

Es necesario entender, que de acuerdo a la Constitución Política de 1991, el Consumidor goza de la protección de dos tipos de Derechos. Por una parte, está la protección de Derechos Fundamentales, tales como la vida, la salud y la privacidad entre otros. Por otra parte, la Constitución de 1991 protege otro tipo de Derechos que, pese a no ser fundamentales en sí mismos, son de vital importancia para el Consumidor y el funcionamiento del mercado. Dicha protección se caracteriza por la necesaria intervención del Estado. En este sentido el Art. 78 inciso $1^{\circ}$ de la Constitución indica que la Ley regulará el control de calidad de bienes y servicios ofrecidos y prestados a la comunidad, así como la información que debe suministrarse al público en su comercialización. En palabras de la Corte Constitucional (Sentencia C-1141 de 2000), "la Constitución ordena la existencia de un campo de protección a favor del consumidor, inspirado en el propósito de restablecer su igualdad frente a los productores y distribuidores, dada la asimetría real en que se desenvuelve la persona que acude al mercado en pos de la satisfacción de sus necesidades humanas. Sin embargo, la Constitución no entra a determinar los supuestos específicos de protección, tema este que se desarrolla a través del ordenamiento jurídico. El programa de protección, principalmente, se determina a partir de la ley, los reglamentos y el contrato. Es claro que la fuente contractual debe interpretarse de conformidad con los principios tuitivos del consumidor, plasmados en la Constitución (...). La 
Constitución delimita un campo de protección, pero el contenido preciso del programa de defensa del interés tutelado, es el que se desarrolla y adiciona por la ley y por otras normas y fuentes de reglas jurídicamente válidas. En particular, trazado el marco constitucional, a la ley se confía el cometido dinámico de precisar el contenido específico del respectivo derecho, concretando en el tiempo histórico y en las circunstancias reales el nivel de su protección constitucional".

Es de anotar que el contrato sigue siendo una fuente de regulación de las relaciones comerciales entre los operadores económicos y el consumidor, pero, a diferencia del modelo liberal clásico, aquel se encuentra restringido por los criterios del legislador, la administración y la jurisdicción. En el caso de la relación banco-consumidor financiero, es la ley 1328 de 2009 la que se encarga de establecer obligaciones a los bancos para la protección del consumidor bancario. El Congreso de la República, en el primer debate manifiesta la necesidad de protección al consumidor financiero. En palabras del Legislador "[u]no de los propósitos de la regulación financiera, radica en equilibrar los intereses de las entidades financieras y de los consumidores de los productos y servicios que estas proveen. En este sentido, fortalecer el régimen de protección de los consumidores resulta de vital importancia, en la medida en que es una realidad que los consumidores financieros (usuarios, clientes y potenciales clientes) afrontan desequilibrios en cuanto a capacidad económica, nivel de información, educación y poder de negociación, respecto de las entidades financieras. 
Se requiere entonces, sin perjuicio de los evidentes avances que se han logrado en la materia, tanto a nivel normativo, como de supervisión y de mejores prácticas en las mismas entidades, que el marco legal protector de los derechos y garantías de los consumidores financieros, los consagre claramente sin desconocer la autonomía de los consumidores para seleccionar los productos utilizados"7.

Entonces de aquí surge la necesidad de revisar algunos mecanismos para proteger al cliente que se encuentra una posición desfavorable frente a la del banco. Estos mecanismos pueden reducirse a dos. El primero de ellos recae en la facultad del juez de declarar nulas las cláusulas en los contratos que son manifiestamente desiguales en la relación contractual. El segundo mecanismo, se da a través de la ley, cuando planta normas imperativas, que no dan cabida a una modificación por parte de los particulares. Este tipo de leyes son las que en alguna medida prohíben a los bancos algunas prácticas (RODRíGUEZ AZUERO, 2009: Págs. 178 y s.), tal como la ley 1328 de 2009.

\section{B. Los Contratos Bancarios en la ley 1328 de 2009}

La ley 1328 de 2009 en su artículo segundo define los contratos de adhesión como aquellos "elaborados unilateralmente por la entidad vigilada y cuyas cláusulas y/o condiciones no pueden ser discutidas libre y previamente por los

\footnotetext{
${ }^{7}$ CONGRESO DE LA REPÚBLICA, Ponencia para Primer Debate Proyecto 282 de 2008 Cámara, 286 de 2008 Senado por el cual dictan normas en materia financiera, de seguros, del mercado de valores y otras disposiciones, en Gaceta del Congreso No. 341 de 2008.
} 
clientes, limitándose éstos a expresar su aceptación o a rechazarlos en su integridad."

Es importante determinar si existe una relación entre el concepto legal, el jurisprudencial y el administrativo respecto a los contratos de adhesión. En la Jurisprudencia de la Corte Suprema de Justicia hay que tener en cuenta que a partir de la jurisprudencia de 1974, se plantean dos teorías desde las cuales se pueden trabajar los contratos de adhesión (explicadas anteriormente), lo relevante en este punto es mencionar que la ley 1328 tiene afinidad con la teoría que indica que la APV del contratante (que no es el banco), está restringida a elegir si contrata o no, faltándole a este la posibilidad de discutir las cláusulas del contrato. Esta teoría es la Teoría contracual de los actos de adhesión que indica que estos contratos de adhesión, son verdaderos contratos ya que el individuo conserva la facultad de contratar o no.

La jurisprudencia de la Corte Suprema se ha pronunciado en el tema de los contratos de adhesión, en el sentido que, al tener la entidad bancaria la facultad de redactar los contratos (contratos de adhesión), le preocupa a la Sala que se generen conductas abusivas. La Corte indica que "(...) en la formación de un contrato y, específicamente, en la determinación de "las cláusulas llamadas a regular la relación así creada, pueden darse conductas abusivas", ejemplo prototípico de las cuales "lo suministra el ejercicio del llamado poder de negociación por parte de quién, encontrándose de hecho o por derecho en una 
posición dominante en el tráfico de capitales, bienes y servicios, no solamente ha señalado desde un principio las condiciones en que se celebra determinado contrato, sino que en la fase de ejecución o cumplimiento de este último le compete el control de dichas condiciones, configurándose en este ámbito un supuesto claro de abuso cuando, atendidas las circunstancias particulares que rodean el caso, una posición de dominio de tal naturaleza resulta siendo aprovechada, por acción o por omisión, con detrimento del equilibrio económico de la contratación"(CSJ - Cas. Civ. 21 de Mayo de 2002, Exp. 7288).

Asimismo la CSJ indica que así el consumidor bancario mantenga la facultad de decidir si contrata o no, esto no implica que la entidad financiera no tenga posición dominante sobre le usuario bancario, lo que implica que se pueden generar cláusulas abusivas, que haces que la relación contractual presente un desequilibrio que perjudica al dicho consumidor (CSJ - Cas. Civ. 21 de Mayo de 2002, Exp. 7288).

La Superintendencia de Industria y Comercio, en su concepto 22009074985-004 del 26 de noviembre de 2009, indica que "El contrato de adhesión evolucionó al contrato estándar permitiendo la normal circulación de bienes y servicios en una economía de masa. Es decir, un contrato de adhesión que se utiliza, a partir de cláusulas generales y uniformes, para la contratación masiva de bienes y servicios, corresponde a un contrato estandarizado" 
De igual forma dice la Superintendencia, que dichos contratos de adhesión son un instrumento para realizar operaciones en masa, y que por ser así, se consideró en un primer momento como una expresión del abuso de posición dominante, razón por la cual dicho desequilibrio contractual se busca remediar a través del desarrollo de principios constitucionales como la buena fe, el abuso del derecho, entre otros.

Igualmente la Superintendencia desarrolla en el concepto la idea de que dichos contratos de adhesión -distanciándose un poco de la CSJ-, no son simplemente una representación del abuso de posición dominante, sino que por el contrario son un instrumento importante en el tema de la contratación en masa, además se manifiesta que el contrato no solo plantea situaciones de desequilibrio, sino que lo que busca es llevar a cabo las relaciones económicas contemporáneas.

Lo que se puede observar desde estos tres ámbitos, legal jurisprudencial y administrativo, es que la ley y la jurisprudencia buscan en alguna medida la protección de los derechos del consumidor, sin embargo, la Superintendencia, mira el tema desde un punto de vista más económico, buscando la protección de las dinámicas del mercado.

Como se puede observar, el legislador prevé la alternativa o el uso de dichos contratos, pero en el desarrollo de la misma ley restringe la elaboración de los 
mismos. En este sentido la ley 1328, en su artículo 11 establece unas prohibiciones respecto al uso de ciertas estipulaciones que:

a. Prevean o impliquen limitación o renuncia al ejercicio de los derechos de los consumidores financieros.

b. Inviertan la carga de la prueba en perjuicio del consumidor financiero.

c. Incluyan espacios en blanco, siempre que su diligenciamiento no esté autorizado detalladamente en una carta de instrucciones.

d. Cualquiera otra que limite los derechos de los consumidores financieros y deberes de las entidades vigiladas derivados del contrato, o exonere, atenúe o limite la responsabilidad de dichas entidades, y que puedan ocasionar perjuicios al consumidor financiero.

e. las demás que establezca de manera previa y general la Superintendencia Financiera de Colombia. ${ }^{8}$

Es importante tener en cuenta que el banco igualmente no vaya a caer en el error de generar Cláusulas predispuestas que en algunos casos puede llevar al desequilibrio contractual.

Por lo anterior deben las partes tener en cuenta los principios contractuales generales, y especialmente el de buena fe contractual. La Superintendencia

\footnotetext{
${ }^{8}$ Consecuencia jurídica de ello sería que Cualquier estipulación o utilización de cláusulas abusivas en un contrato se entenderá por no escrita o sin efectos para el consumidor financiero.
} 
Bancaria sostuvo que el Estatuto Orgánico Financiero, establece la obligación de obrar no solo dentro del marco de la ley, sino dentro del principio de buena fe y de servicio a los intereses sociales. (Consejo de Estado. Sala de lo Contencioso Administrativo. Sección Cuarta. C.P. Delio Gómez Leyva. Sentencia del 19 de mayo de 2000. Expediente No. 9732.)

\section{Principios orientadores de la ley 1328}

El artículo $3^{\circ}$ de la ley 1328 habla acerca de los principios que van a regir las relaciones entre consumidor financiero y banco. Del artículo se puede deducir que no solo pretende enunciar deberes del Banco, sino también derechos que adquiere el consumidor por el solo hecho de acceder al sistema financiero tal y como está planteado. La disposición enuncia como primera medida el deber de diligencia de los bancos al momento de ofrecimiento de sus productos y de la prestación del servicio a los consumidores, pero esto lleva implícito el derecho de los mismos (los consumidores) de que la información que reciban sea verídica, y completa. De igual manera se especifica el derecho de los consumidores de ser tratados con respeto y de buscar en la relación contractual una satisfacción de las necesidades del consumidor. Respecto al segundo principio este se concentra en la facultad del consumidor de escoger a su contratante.

En cuanto al tercer principio este es bien importante ya que se especifica claramente el deber de las entidades financieras de suministrar al consumidor una 
información cierta, suficiente, clara y oportuna, lo que se traduce en el derecho del consumidor de que reciban la información de la manera correcta, tal y como lo estipula la ley, aclarándole al consumidor la oportunidad para conocer sus derechos, sus obligaciones y los costos de las operaciones q tramitan.

De igual manera en el artículo se plantea la responsabilidad de los bancos de tramitar las quejas y reclamos de manera eficiente, cumpliendo con los plazos y las condiciones que les plantea la entidad que los vigila. Esto es bueno ya que gracias a esto el servicio que presta la entidad financiera se mejora porque cada vez que haya un contratiempo con un usuario al mejorarlo con este, mejora con los usuarios en general.

Acerca de los conflictos de intereses que se presentan, la ley deja claro que la entidad financiera debe resolverlos de manera transparente e imparcial.

El último de los principios que menciona la ley en este articulo 3, es uno de los más importantes ya que además de plantear que los usuarios deben estar plenamente informados acerca de los servicios y productos que presta la entidad, plantea que los usuarios deben conocer los mecanismos establecidos para la defensa de sus derechos. Al estar informado, este tiene la posibilidad de defender sus derechos, y de igual manera prevenir que le sean vulnerado antes incluso de que los transgreda la entidad vigilada. 
Al plantearse esta situación es interesante la manera en que se protege al consumidor bancario, en el sentido de que la entidad vigilada debe al tiempo en que realiza el formato del contrato, abstenerse de plantear cláusulas que vayan en contra de los derechos de los mismos (cláusulas predispuestas). De igual manera lo protege al consumidor bancarios ya que le da aplicación a los principios que se plantean en el articulo 3 en el sentido de que el cliente tiene el derecho a estar informado de la totalidad de las cláusulas estipuladas en el contrato, que incluyen las tasas de interés, los derechos y obligaciones de ambas partes, entre otras.

Lo anterior conduce a que el consumidor bancario tenga la posibilidad de satisfacer sus necesidades digamos crediticias, por medio de los contratos que le plantea el banco.

El artículo 11 es claro al indicar que las cláusulas o estipulaciones contractuales no pueden ser planteadas de manera abusiva, es decir, no pueden ir en contra de los derechos de los usuarios. Esto se refleja cuando la norma indica que las cláusulas no pueden referirse en ningún momento a acciones que hagan que los consumidores bancarios tengan limitaciones en el ejercicio de sus derechos. Igualmente se plantea que la entidad financiera no puede exonerarse de la responsabilidad que surja de sus acciones y que pueden desembocar en el quebrantamiento de los derechos de los usuarios. 
Respecto al artículo 12 de la ley, básicamente lo que debe resaltarse es que los derechos del consumidor financiero priman sobre los de la entidad. También debe tenerse en cuenta que en este articulo se refiere indirectamente la norma a la ética del banco, es decir, el banco no puede ni debe actuar en contra de los principios constitucionales.

\section{Algunas cuestiones sobre la ley 1328}

Es claro que las leyes no son retroactivas. Sin embargo el hecho de que esta ley empezara a regir desde el primero de julio del 2010, implico en su momento que las entidades financieras no tenían las obligaciones que plantea la ley, por tanto en muchos sentidos pudo haber transgredido los derechos de los consumidores, y sin embargo el Gobierno no hizo nada en el momento, aunque por otro lado aquí se retoma lo que decía al inicio, y es la actuación inversa del Estado, en el sentido de que la Corte era la que hacía las veces de "legislador" en el tema, y por esto era que las entidades financieras se frenaban un poco a realizar los contratos a su manera desprotegiendo los derechos de los usuarios.

De lo anterior quedan entonces unas preguntas sin resolver ¿Cómo se regulara la protección al consumidor bancario antes de la expedición de la ley 1328 de 2009 ? ¿Sera posible que la protección al consumidor antes de la ley 1328 se siga dando en los términos de la actuación inversa del Estado, y la protección la siga dando la jurisprudencia? 
Otro punto es que la entidad bancaria tenga la obligación de realizar el formato de los contratos, ya si esta sigue haciendo los contratos, estos nunca van a ser contradictorios a sus intereses, lo que lleva a que el usuario va a tener que seguir adhiriéndose a la voluntad del banco, sin tener la posibilidad de cambiarla. Esto no implica desde luego que el banco vaya a ser arbitrario al realizar los contratos, ya que la ley se lo prohíbe y le da unas pautas claro para realizarlo, pero de igual forma el Banco no va a realizar el contrato buscando defraudar sus intereses, por el contrario puede buscar la forma de al realizar el formato del contrato, evadir el mandato de la ley, y redactar algunas cláusulas abusivas.

La ley es especifica en que los contratos de adhesión únicamente quedan en manos de los bancos, y aunque se presentan prohibiciones de cláusulas abusivas en los contratos, los usuarios van a ver restringida su APV esto debido a que la posibilidad sobra la elección del contrato se va a ver reducida a aceptar los términos del mismo o a rechazarlos, sin tener la posibilidad de transarlos.

Respecto al artículo 12 debería dejarse claro que las cláusulas abusivas no deberían solo restringirse desde el momento de la entrada en vigencia de la ley, sino que debieron sancionarse desde el momento en que el legislador vio que la entidad financiera sacaba provecho de la situación de inferioridad del usuario. 


\section{SÍNTESIS}

El Ordenamiento Jurídico Colombiano consagra la calidad de Interés y Servicio Público a aquellas actividades financiera, aseguradora, bursátil o que tengan que ver con el manejo o flujo de capitales. Dichas actividades, en virtud del artículo 335 de la Constitución Política, pueden ser objeto de intervención estatal en sus operaciones, incluyendo la contractual.

Siguiendo el criterio de la Cláusula General de Competencia, el Estado se encuentra legitimado para actuar en una secuencia legislativa-administrativajudicial. Sin embargo, un rasgo característico del desarrollo de las intervenciones del Estado colombiano en la operaciones bancarias ha sido la fuerte presencia de los órganos jurisdiccionales en la restricción y orientación de las actuaciones de los bancos frente a los consumidores, a través de la Corte Constitucional -quién se ha manifestado en virtud de protección de Derechos Fundamentales- y de la Corte Suprema de Justicia -caracterizada por el uso de la interpretación como herramienta para el reequilibrio de las relaciones contractuales.

Solo hasta el año anterior, el Legislativo ha proferido la ley 1328 de 2009, la cual se encarga expresamente de regular las relaciones entre el Banco y el Consumidor, especialmente en materia de contratación. Dicha ley consagra unos principios y unas obligaciones a los bancos en pro del consumidor, sin embargo, deja algunas cuestiones sin resolver, especialmente sobre la retroactividad de 
normas en algunas relaciones bancarias y en cuanto la protección de intereses de los bancos en el diseño de los contratos estándar o de adhesión.

Tanto los principios como las obligaciones consagradas por la ley 1328 de 2009 constituyen una limitante de la Autonomía de la Voluntad Privada, es decir, los bancos no pueden escoger plenamente las normas para el diseño de sus contratos. Esta restricción se verá, a futuro, en la elección de los estándares internacionales diseñados para los bancos. Si dichos estándares constituyen herramientas más adecuadas para la protección de consumidores y usuarios financieros, podría decirse que habrá una elección preferente de estos estándares. $\mathrm{Si}$, en cambio, dichos estándares tratan indiscriminadamente a los clientes corporativos y a los consumidores y usuarios financieros, y los estándares tienden hacia una desprotección de los últimos, aquellos no podrán ser aplicados en Colombia, en virtud del carácter imperativo de las normas contenidas en la ley 1328 de 2009, las cuales protegen no sólo el interés de los consumidores sino también el Interés Público.

\section{REFERENCIAS}

ALTERINI, Atilio; LÓPEZ CABANA, Roberto. La Autonomía de la Voluntad en el Contrato Moderno, Ed. ABELEDO-PERROT, Buenos Aires, Argentina, 1989, Págs. 36 y 37. 
BARBIE, Eduardo Antonio. Contratación Bancaria. Editorial Astrea. 2002. Ciudad de Buenos Aires. Pág. 69 y 70.

DE BUEN LOZANO, Néstor. LA DECADENCIA DEL CONTRATO. Ed. Porrúa, S.A. Av. República de Argentina, 15. México, 1986.

DIEZ ESTELLA, Fernando. Derecho Mercantil. Recuperado el 15.08.10, de http://fernandodiezestella.com/derecho mercantil/Tema 15.pdf.

IBAÑEZ NAJAR, Jorge Enrique. El tratamiento constitucional de la actividad financiera. Temas de derecho financiero contemporáneo. Editores: Sergio Rodríguez Azuero, Erick Rincón Cárdenas, Juan Jacobo Calderón Villegas. Editorial Universidad del Rosario. Año 2006. Pág. 73.

MARTINEZ NEIRA, Néstor Humberto. Derecho Financiero Comparado. Sistemas Financieros. Biblioteca Felaban. 1994. Pág. 7.

MONROY CABRA, Marco Gerardo. ¿ESTA EN CRISIS EL PRINCIPIO DE LA AUTONOMIA DE LA VOLUNTAD? Revista de la Academia Colombiana de jurisprudencia. Julio-Diciembre. 1980 Pág. 102. 
NAMEN VARGAS, William. LA LIBERTAD CONTRACTUAL: NEGOcíO JURIDICO Y CONTRATO. Consejo Superior de la Judicatura. Revista Judicial. Diciembre 2009.

RODRIGUEZ AZUERO, Sergio. Contratos Bancarios y su significación en Latinoamérica. Sexta Edición. Legis. Agosto 2009. Pág. 114.

SUESCUN MELO. Jorge. La Aplicación del Postulado de la Autonomía de la Voluntad en la Contratación de las Entidades estatales, en Derecho Privado: Estudios de Derecho Civil y Comercial Contemporáneo, Ed. Legis, 2da. Edición, Bogotá, Colombia, 2005. 